Ciência e Natura, Santa Maria, v. 37 n. 3 esp. 2015, p. 80-91

Revista do Centro de Ciências Naturais e Exatas - UFSM

ISSN impressa: 0100-8307 ISSN on-line: 2179-460X

\title{
ciênciaenatura
}

\section{Pathology of the Model of Wind Turbine Manufacturing Technology Transfer in Iran}

\author{
Sajjad Rahmani ${ }^{1,}$, Mohammad Hassan Fazli ${ }^{2}$
}

${ }_{1, *} \cdot$ M.A student of Technology Management, Iran University of Science and Technology

2. M.A student of Technology Management, Iran University of Science and Technology

\begin{abstract}
Attention to Renewable energy resources, first, because of the increasing environmental pollution and climate change, and the second due to reduce supplies of fossil fuels, is one of the policy priorities in many countries, especially developed countries has become. because of a broad range of environmental damage and international commitments, developing countries have been obliged to enter into this field. attention to the gap between developed and developing countries in the field of renewable energy technologies, technology's transfer the first and most effective way for developing countries in this field. Iran also is no exception and takes a step in this direction. given the obstacles and challenges that there are in developing countries for technology's transfer, this paper a review of a project comes in technology's transfer in the field of wind turbines. the main reasons for the success of the project are indentified and improved model is proposed for future project.
\end{abstract}

Keywords: Technology; Technology's transfer; Wind turbine. 


\section{Introduction}

$\mathrm{T}$ oday, environmental pollution is a major challenge facing humanity and has become a worldwide policy making priority [1]. Rate of Greenhouse gas emissions is one of the most obvious pollution that has a lot of adverse effects on the environment. The highest rate of greenhouse gas emissions is related to energy production from fossil fuels, so that $84 \%$ of greenhouse gas emissions in the world in has been in 2009 for energy production $[2,1]$. In Iran, more than $90 \%$ of the greenhouse gas is generated by the energy sector [3]. Also The highest emissions of greenhouse gas is related to developing countries, so that according to the predictions made, until 2040, these countries will produce $69 \%$ of all greenhouse gas [2], hence developing countries, especially in the energy sector, play a crucial role in preventing the crisis in the coming years.

Based on the above mentioned challenges, paying attention to renewable energy sources and policies of gradual removing fossil fuels has found growing importance and the projects related to decreasing pollutants have turned into cross sectional stated from projects state [1]. Now paying attention to environmental issues affect the economic growth and is considered as a macroeconomic indicator. Therefore, policy making for environmental issues and emphasis on planning to reduce pollutants, especially in the energy sector, is one of legal and economic requirements of all countries, both developed countries and developing countries because in some international treaties such as the United Nations Framework Convention on Climate Changes, countries are committed to cooperate to reduce greenhouse gas emissions [3].

However, developing countries, including Iran, due to economic constraints and other limitations in the field of international relations, and also because of the lack of international commitments on reducing pollutants, have not entered this field seriously do not have and longterm planning for it [3 ]. On the other hand, due to technological gap between developed and developing countries in the field of renewable energy technologies, costs of research, development and deployment of these technologies for developing countries is heavy and because of their economic reliance on fossil fuels, the driving force for development renewable technologies does not exist in these countries.

Technology transfer, whether in the field of renewable energies or in other areas of technology, is the best and most efficient way to cover this gap between developed countries and developing countries. Therefore, the best way to prevent environmental disaster in the future can be development of technology transfer projects from the new energy technologies to developing countries. Obviously, the transfer of technology is not just to transfer physical facilities and equipments [4] and it is effective if done properly and completely.

In the present paper it is tried to, based on current models of technology transfer in the world, and also with regard to the particular circumstances of Iran country, to investigate one of technology transfer projects in the field of Wind turbines and conduct pathology on and ultimately provide an improved model for future projects.

In the following, we will first by looking at the literature in the field of technology transfer, a selection of popular models of technology transfer is provided and the factors that should be considered in each are referred to. Section three is devoted to a short description of the methods used for this study. In Fourth section after looking at wind energy industry, wind turbine technology transfer project that was initiated by Parseh company is reviewed and a model for the transfer of technology is presented. Then, according to the project experiences and looking at the current models of technology transfer, problems of the project are studied and improved and finally a model is proposed for future technology transfer projects. 


\section{Literature Review}

\subsection{Technology}

In a general view, the technology can be defined in three ways: product technology, process technology and technology of management. Product technology is the knowledge that is used in the manufacture of a product. Process technology is the knowledge used for organizing and the production of raw materials or the way service is provided, and management technology is the knowledge of business, and how to use resources as efficiently to competition [5].

Although the technology is often regarded as the hardware, but the technology is made up of several components, one of which is hardware. Other components include information (including procedures, manuals and other documentation), Man (experience, skills, tacit knowledge, creativity, etc.) and organization (processes, management practices, etc.) [6,5]. By combining these components certain functions for the technology is realized.

\subsection{Technology transfer}

Technology transfer can be defined as a process that allows possibility of taking advantage of one organization (which has developed in accordance with the objectives of that organization) in other organizations (with other goals) [7]. This subject, due to its close relationship with economic growth is always attractive for policy makers, economic activists, and business executives. However, the technology transfer does not mean just transfer of equipment or products, but the required knowledge and other technology components explained in definition of the technology,should be transferred to the recipient or created in it, so that the mentioned the technology is effective. Despite the positive effects of technology transfer for recipients of technology, if the transfer process is not done correctly and completely (specially in transfer of technical knowledge), it can even have negative effects on the economy of receptor country $[5,4]$

\subsection{Methods of technology Transfer}

Technology transfer has various ways that depending on the circumstances of each transfer, a special type is selected. Technology transfer methods can be named as follows:

- Foreign Direct Investment: In this method, the holder of technology, directly establishes equipment and technology in the recipient country and ownership of the technology and possibility of exploiting it is totally for the country giving the technology.

- Joint Venture: in this method The recipient country has share in investment and thus in ownership of technology (usually greater share is for the recipient country).

-License: In this method the recipient country in the limited time and to a limited extent, under the brand name holder of technology, can have some level of technical knowledge in addition to the equipments.

- Turnkey Projects: In this mode, the receiver country does not have any involvement in the transition process and the owner of the technology transfer does all phases of transfer such as facilities manufacturing, technology implementation, preparation of instructions and so on, and recipient country just receives project as ready for operation [8.7]

\subsection{Technology transfer models}

Many models have been proposed so far for technology transfer. It should be noted that the model represents a set of components and relations between them and states general framework of energy transfer, but the method indicates the type and form of technology transfer [9]. In fact, one of the components of a model of technology transfer is the transfer method.

In this part three common examples of popular models in the literature on technology transfer is presented and finally project sample is investigated based on these models.

\section{- $\quad$ Model of Malik}

In this model technology transfer has been likened to a communication process. The 
components of this model are message sender, message recipient and message (technology) and successful transfer of technology depends on correct transfer and understanding of the data exchanged between technology recipient and giver [9.4].

\section{- Model of Gilbert}

in this model considering the two determining factors, based on four basic methods, appropriate technology transfer method is selected. Systems (or environments in which the transfer takes place) are divided into four categories: public systems, passive systems, cooperative Systems and anticompetitive systems. Appropriate methods of technology transfer in the system is as follows:

- General Systems: knowledge needed by public information is obtained through general information such as research publications, training courses, and free copies.

- Passive systems: in these systems technology receiver system acquires the desired science and technology as a passive, such as turnkey projects and receiving license.

- Cooperative System: if the system is based on cooperation, both receiving and holder have an active role in transfer process, like joint investment.

- Anticompetitive systems: in this case access to technology without the consent of the technology holder and through ways such as industrial espionage, reverse engineering, and imitation.

Two factors that must be considered for selecting the appropriate method of transmission include:]

1. mutual desire and access to sources of technology: if the technology holder does not wish to transfer or having access to technology is not possible, the public and anticompetitive practices should be used. The technology resource consent is not required in this case.

2. Control of technology source on its use: if the holder has acquired control over the use of technology, anti competitive and cooperative practices are suitable and if the holder's control over the use of technology is poor, passive and public methods will be appropriate [9.8].

\section{- Model 7c}

This model has seven components that must be considered in the process of technology transfer. The seven component (c is the first letter of their Latin names), are as following:

1. context

Context factors are related to the environment in which technology transfer occurs, such as infrastructure, management skills, qualified manpower, time course, etc.

\section{Challenges}

Challenges represent a variety of obstacles in the way of a successful technology transfer,such as lack of suitable information, economic problems, communication problems, and political and legal obstacles that in the introduction some of the challenges facing developing countries were noted.

3. Choice

in choice process several factors should be taken into consideration such as the correct definition of requirements, identification of competing technologies, and technology life cycle of knowledge of technology holders.

\section{Certainty}

Technology transfer should not take place in conditions of extreme risk and should have a good level of stability and certainty for correct planning. For example, legal and economic stability in the recipient country and receiving adequate information. High risk affects the transition process.

\section{Communication}

In the previous sections it was explained that the information has an important role in the success of the transition process. Given that technology transfer projects often have long distance and they are long term in terms of time, existence of communication channels at the beginning, during and after the technology transfer are necessary.

\section{Capacity}

The capacity of the recipient country has a crucial role in the selection of a technology transfer project. Many studies have been conducted on the capacity and it is sometimes also referred to as the capacity for innovation [11]. 
Many factors affect the overall capacity of the receiver that can be summarized in the innovation system.

7. Commitment

both sides of Technology transfer, that is the receiver and transmitter must have commitment in the entire process for overcoming barriers and effective performance of technology transfer [11]

\section{The method of study}

In this paper, one of the technology transfer projects in the country, which is related to the construction of wind turbines for electricity generation technology has been studied. First, general information about the mentioned project is brought by the authors then they analyzed that on the basis of their components and their relationships.

In cases where more detailed information is required, the complementary information was taken from people of the company doing the Project ( Parseh ebtekar company).

After summing up all the information and an interview with one of officials of company, the project came in the form of an abstract model and was pictured.

According to the explanation about this model and its difference between the model and the proposed method, the objective of modeling this project has been identifying its components and the main actors and analysis of the relationships among them.

Since the present projects has not been completely successful, attempt was made to investigate the causes of failure and include them as a model. So in the end, after reviewing the modeled project, and matching it with the standard models presented in the previous section, shortcomings coming to mind of the authors in the project are found and at the end the improved model that covers shortcomings is presented.

\section{Technology Transfer in the wind turbine industry}

\subsection{Taking a look at wind energy}

As mentioned in the introduction, the use of renewable energies, particularly in developed countries is increasing. Wind energy is one of the renewable energy whose share in electricity generation, according to the progress made in the construction of wind turbines and power plants, is growing and looking at the statistics, the annual increase in the share of wind power in electricity production is observed. For example, in 2012 the proportion of wind power generating capacity by 2011 , had increased $19 \%$. China and America are ranked first and second in the world in wind power production, followed by Germany with a considerable distance in the third rank. America has had the most new installed capacity in 2012 and this success has been due to factors such as growth in domestic production and development of turbine technology that increased efficiency and reduce the cost of wind power [12].

The advantages of wind power plants can be mentioned the following:

- Ease of installation and setting up compared to fossil fuel power plants

- process Installation and more productivity

- Low level of land occupation

- Ability of exploitation in various capacities pollution

- The absence of any environmental - Visual appeal [14.13]

\subsection{Wind power in Iran}

Iran since started producing electricity from wind energy since 1373 by installing two wind turbines with a capacity of 500 kilowatts imported from Denmark in Manjil andR. Now Renewable Energy Organization of Iran (SUNA) has two 30-megawatt wind farm and the $100 \mathrm{MW}$ Manjil Binalud under construction and development Its turbines of $660 \mathrm{~kW}$ and technical knowledge acquired through the purchase of the license from the Danish company and are produced by SADID Industrial Group (Sba niroo) within in the country. It should be mentioned that no megawatt wind turbines has been imported or installed in the country so far. 
The table below shows the statistics for the construction of non public wind power plants in Iran, compared to other visible renewable energies [15]:

Table 1: Statistics for permission to establish a non-renewable energy power plants in Iran

\begin{tabular}{|c|c|c|c|c|c|c|}
\hline row & $\begin{array}{c}\text { Development } \\
\text { stages of power } \\
\text { plants }\end{array}$ & Wind(MW) & Solar(MW) & Biomass(MW) & Hydropower(MW) & Total (MW) \\
\hline 1 & In operation & $28 / 4$ & .............. & $1 / 6$ & $\ldots \ldots \ldots \ldots \ldots \ldots \ldots$ & 30 \\
\hline 2 & $\begin{array}{c}\text { purchase } \\
\text { contract of } \\
\text { Power traded }\end{array}$ & 579 & ….......... & 12 & ............ & 591 \\
\hline 3 & $\begin{array}{c}\text { Having } \\
\text { approval of } \\
\text { construction }\end{array}$ & 5189 & $495 / 1$ & 5 & $10 / 87$ & $5699 / 18$ \\
\hline 4 & $\begin{array}{l}\text { Studying the } \\
\text { feasibility }\end{array}$ & $3226 / 5$ & 345 & $9 / 7$ & $1 / 4$ & $3982 / 6$ \\
\hline 5 & $\begin{array}{c}\text { Licenses } \\
\text { expired }\end{array}$ & $572 / 5$ & …........ & $124 / 2$ & $29 / 4$ & $726 / 1$ \\
\hline & $\begin{array}{c}\text { Total of } \\
\text { capacity of the } \\
\text { records formed } \\
\text { until today }\end{array}$ & $9997 / 4$ & $840 / 1$ & $152 / 5$ & $40 / 887$ & $11028 / 8$ \\
\hline
\end{tabular}

Since Iran is now importing the wind turbine industry from companies having the industry in Europe, production of this product in the country can prevent the outflow of foreign exchange, employment, promote technology exports to countries in the region (due to very low cost), bringing exchange technology and the other benefits. Obviously, as explained in introduction part, given the technological gap between Iran and other countries that have this technology, technology transfer and is appropriate shortcut way and the first attempt to develop this technology in the country.

According to the wind atlas under the country, to supply wind turbines heavy importing is very needed; If the import is complete, for services related to providing maintenance and after-sales service, a significant number of projects will be imposed; as a result increase cost of energy production. It is true if Iran has a high ability to produce large parts of plants such as wind towers, blades and foundation and expertise in vacuum science and technology in the production of the turbine [14]. at the present time, the group Mapna produces turbines with kilowatt capacity, but still in the country level, producing a megawatt turbines does not exist. Two-megawatt turbines without gearboxes, on the one hand because of being without gearboxes, and on the other hand due to very detailed and advanced design are the best type of turbine technology in the world. The technology transfer projects of these turbines have been done recently in the country and are discussed in the next section.t

\subsection{Case of Study: technology transfer of Two- megawatt turbines without gearbox from Avantis company in Germany}

\subsubsection{Introducing the parties of project}

Avantis Energy company was founded in 2004 and has experienced managers who has some 30 years experience in other wind turbine manufacturers. In 2009, this company has received certification of testing their turbines. Among the company's activities include the installation of wind turbines in China, consisting of 80 wind turbine in Thailand and installing 200 wind turbines Russia. 
Parseh ebtekar company in 1380, in order to provide consulting and engineering projects of renewable energy, mechanical and electrical installations and information technology and related industries, and industrial property was registered in the Companies Registration Office. The company holds first license of manufacturing megawatt wind turbines in the Middle East.

\subsubsection{Technology transfer project}

Two-megawatt turbine technology transfer has been carried out by purchasing the license. Iranian side also has the right to sell under license to Iranian customers and clients in the region.

The process passed through mentioned transmission project has been carried out according to the following steps:

1. Building contract between counselor and client

2. Providing the file of information of German wind turbine manufacturers to the applicant

3. Obtaining the applicant's willingness to invest in the establishment of the wind turbine industry in Iran

4. Providing the German group visit from production sites in Iran

5. Exchanging information with the German side to formulate pre-contract

6. Performing Formalities of dispatch, inspection and contract in Germany

7. The arrangements for tendency of the German side for applicants visit from parent Geramn factory and formulating final contract in Germany; in this contract the comprehensive program of establishing stages of manufacturing industry and production of wind turbines are predicted and formulated

8. The arrangements needed for purchase, transfer, and setting up the production line machineries
9. The arrangements needed for transfer of knowledge and technology as well as training of Iranian experts

10. Consulting, installation, commissioning and providing the necessary training in site

The following conditions have been accepted by both parties as side components of the contract:

1. The applicant must have the necessary expertise in this industry, or that it could afford to have a professional service.

2. The applicant must have the necessary investment power and taking required permissions from the relevant authorities for establishing industrial wind turbines. The main requirements include land, infrastructure constructions related to production and storage facilities, purchase of machinery and equipment as needed, financing experts, the German industry and finance projects for the mission in the Iranian experts sent to Germany for training.

3. Consulting company is responsible for planning, coordination, administration and support of the applicant issues for performing all stages of the project.

4. Pieces whose manufacturing does not have economic justification in Iran are imported by German industrialists.

5. In the case of some components, such as towers, etc., which can be manufactured in factories in Iran, the applicant can ignore investing in the project for their production, and assign its production to the domestic workshops.

6. The cost of sending a group of advisers to the applicant along the applicant group to Germany is the applicants responsibility.

7. The costs associated with the visiting the German team in Iran is the applicant's responsibility.

According to the above-mentioned steps and other information that was provided to authors from the authors for this project of technology transfer the model shown in Figure 1 can be 
imagined. It should be noted that this model has been drawn on the basis of activities undertaken.

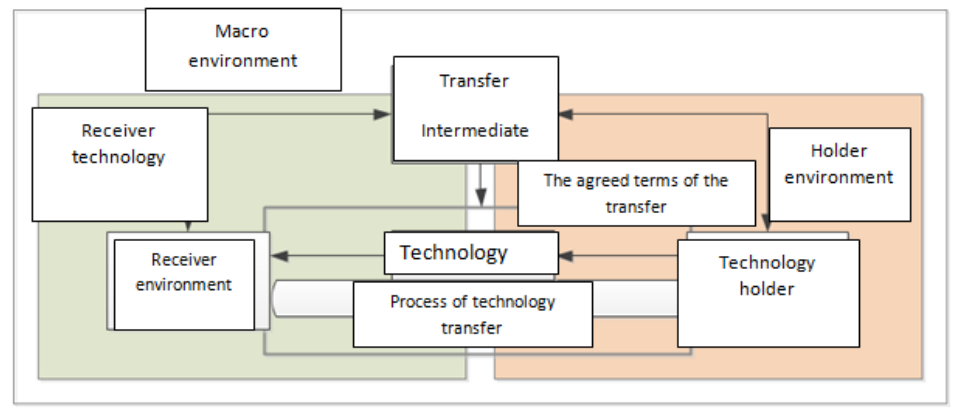

Figure 1: Model of the transfer of technology transfer projects studied.

Components of the model are:

- Owner of technology: Avantis energy company.

- Technology: technology of production and sales under license two-megawatt wind turbines. - The process of technology transfer: ten steps mentioned above.

- Agreed conditions of Transfer: seven cases mentioned above.

-technology receiver: Prseh ebtekar company

- transfer intermediate: consulting company that has the mediating and advisory role. This company has a duty to explain the technology for receiver side, project sides coordination, creating agreement between the parties, facilitate technology transfer and communication between the client and the owner.
- The holder of technology: set of law, political conditions, economic conditions, competition, market and other factors that are affecting the technology holder (the German).

- The receiver technology, law, political conditions, economic conditions, competition, market and other factors that are affecting receiver technology (Environmental).

- Technology receiver environment: set of rules, political conditions, economic conditions, competitirs, market and other factor the affect technology receiver( environment of Iran).

-Macro environment: all the environmental factors that are affecting the parties and joint projects simultaneously (global environment).

- Information: in the figure, the arrows indicates the flow of communications and the effectiveness of the components on each other.

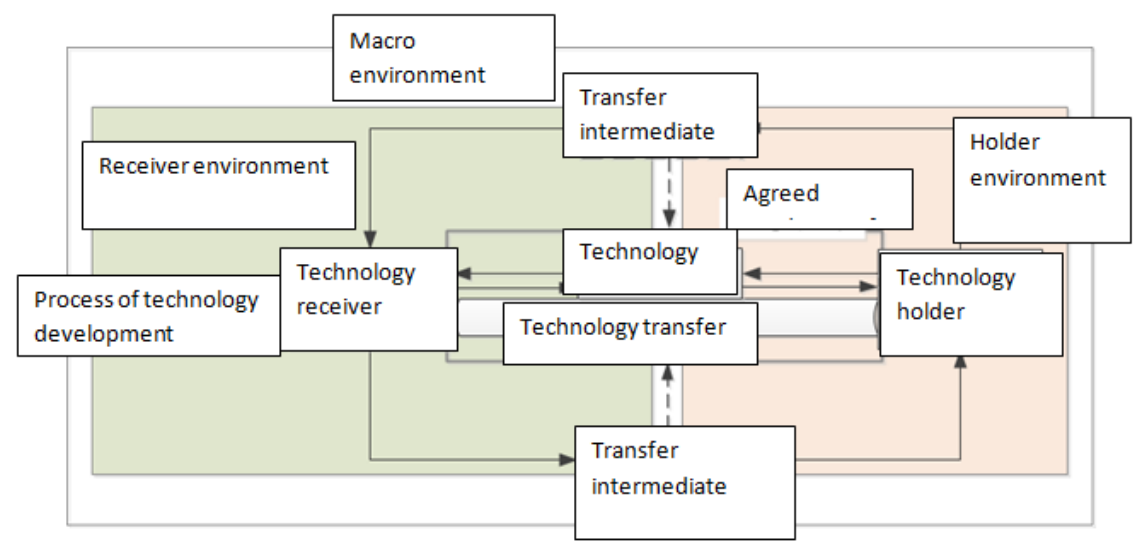

Figure 2- proposed technology transfer model

\subsubsection{Investigation of technology transfer model}

According to the above-mentioned steps and causes of complete and successful nonrealization of the transport projects the following are the most important shortcomings of the model of technology transfer project:

1. The connection between the receiver and the holder of technology is performed only 
through intermediaries (consulting firm). Given the importance of information and communication channels in successful transformation of technology there exist a kind of failure of information and communication in the current process.

2. Environmental factors have not been fully investigated and their effect on the transition process is not clear.

3. The receiver of technology does not impact on control of technology and the holder will receive the exact technology (Regardless of compliance with the environment and the recipient's condition). In general, according to the described models in Section II, the following shortcomings of the model can be outlined:

-according to Mlik model, in this model, the relationship has not been fully and properly established and cannot make sure about correct understanding and feedback of the message.

- The Gilbert model, according to the desire of the parties and the holder control over the use of its technology, collaborative approaches can be replaced, So the receiver can also demand technology in accordance with the wishes and needs and thereby influencing the way technology is not only the holder.

Based on $7 c$, the action of selection in the process of transition has been considered and technology needed to build wind turbines and holder of technology companies have been investigated

Factors that could guarantee mutual commitment, in terms of the transfer agreement have been considered acceptable.

In areas that include environmental factors, especially the two rivals and the government are not paying enough attention. For example, government support of this project is not realized as client expected and competitor entered into the calculation.

Challenges related to communication barriers and creating mutual understanding between the parties to the project, changes in laws and competitor reactions are not properly investigated.

Capacity Iran is not considered appropriate and is remains neglected.

Effective communication due to the existence of recipient on one hand, and the impact of technology on the other hand, has not been established.
Finally ensure that there is full and high economic risk and commercial projects.

According to the model presented in the next section and check out the weaknesses of the project, improved model is proposed for future projects.

\section{An improved model}

The model presented in this section are presented according to the model and the project has been set. This model can be summarized in two parts: components and tips. Figure 2 shows a schematic view of the model.

Components of the model include:

- The holder of technology Country or company which owns the technology and knowhow, and plans to transfer to the economy, competitive advantage, testing technology and reach political goals.

- Technology is a set of hardware (such as machinery and equipment), software agents (such as skills and knowledge), and system information.

- The transition process: a set of steps that need to study and identify the acquisition of technology.

- - the conditions of the transfer agreement: conditions and requirements that the parties to the project, they transfer the obligation to do

Holder of technology: Country or a company that intends to transfer technology and knowledge, and can be benefited from it and can develop that technology in the long-term, in this model the successful of technology requires transfer of knowledge and thus create long-term technological capability in receiver technology.

- By transferring broker: broker is legal entity or individual that facilitates the transition process.

- The holder of technology, law, political conditions, economic conditions, competition, market and other factors that affect the holder of technology.

- The receiver technology, law, political conditions, economic conditions, competition, market and other factors that affect receiver technology.

- Macro environment: all of environmental factors that affect project parties as shared at the same time. 
- Information: on the form, arrows represent the flow of communications and the effectiveness of the components on each other.

- Process technology: The process includes the steps and schedule full absorption technology development and transfer, after completion of the project that can be part of the transition process

Hints that should be considered when using the model are as following:

- 1It should be noted that the motivation of the donor and recipient of technology are different; the recipient usually with goals such as economic growth, technological independence and lack of funding for research and development, applicant the technology While the donor with targets, such as the transfer of obsolete technologies, economic profit and domination over rivals do the transfer. So successful technology transfer takes place when there is a good balance between motives of the parties

2. As noted, the technology is not just hardware in a transmission project, humans, information and organization should be considered. Hardware and data must be transferred fully and human and institutional capacities should also be considered to exploit the technology. If needed human capabilities and organizational requirements do not transfer or create for the operation of a technology technology transfer happen as incomplete and will not yield the desired results [4].

3. Despite receiving of technology is done as passive in some cases but in general, technology transfer if the recipient had no role in its development and technology is not received in accordance with the client's needs and circumstances cannot have much impact on economic growth and sustainable development of the destination country and for a limited period is useful for receptors [10.4].

Generally, prior to the transfer, the current situation should be studied based on Gilbert model to determine the appropriate method of acquiring technology. And the donor required technology is adapted to the needs of the recipient as well.
4. Technology transfer can be done directly or through an intermediary, why the figure is drawn by using the dotted. Intermediaries should only facilitate the communication between the client and the men and if done by an intermediary, its effectiveness is reduced and thus, as mentioned Mlyk model, transmission project success rate will be reduced. In the model, the exchange of information between the receiver and transmitter is established as cyclical and should be continued, even after the completion of transmission,.

5. The holder of the technology and sensor technology may not overlap. If the broker can make a connection between the two environments and also can in transferred under the agreement, close together the requirements of the environment.

6. Environmental factors which should be examined both in person and on the environment:include regulatory requirements, government support, economic conditions, the conditions of international communication, culture, social effects and the capacity will be relevant in the country of destination.. These factors should be together, consistent with the aim of transferring project and transition process

In each project, prioritize and weight of the importance of each environmental factors change. Given that fully coordination of all environmental factors in the donor environment and recipient usually happens rarely, priorities should be determined by environmental factors in each project

7. Technology transfer is the process that also includes transition way, naturally, depending on each technology can make a difference and for it cannot determine certain stages and learning but the important thing is to adapt the process and method of transmission to other components that must be carefully monitored.

.8. Before you decide to start the project life cycle of technology and competing technologies carefully reviewed and selected the best technology. Also according to the chosen technology, technology owners are identified and prioritizing based on receiver. Other 
necessary actions before deciding is to investigate the geography and climate of the recipient to ensure that economic and technological feasibility are desired.

9. The ultimate goal of technology transfer in renewable energy, sustainable development and economic growth.Ability to develop technology and its attraction is a determining factor in the success of the transformation project.Transfer project should be planned in a manner that enables local development and the gradual absorption of acquired technology.

10. There are obstacles in the direction of all arrows model, that their identification is the first step in solving them. For example inefficient information exchange routes, resulting in the lack of understanding of the demands of the parties In the study of environmental factors in each of the obstacles that may create barriers to the successful transfer of technology will be considered.

\section{Conclusion}

In the introduction the importance of the development of renewable energy technologies, energy was mentioned. It also became clear advantage of wind energy compared to other energies. Although diverse portfolio of energy production is considered as an advantage for sustainable development [14], But certainly Iran's gradual entry into the field of wind energy with renewable sources is inevitable. Despite countries which are at high levels in the field of wind energy technology. Technology transfers to Iran could be a shortcut for this technology. Projects in this area have been done and are being done. Based on a sample project that was referred in this article.The main barriers to technology transfer projects and the reasons for lack of success, or in better words, lack of fully technology transfer include: Lack of attention to all areas and environmental factors and their impact on technology transfer, lack of right formation of connection with holders of technology, and then lack of formation of mutual understanding, environmental risk and uncertainty, especially in the field of economics and law, lack of adequate protection by the government, no competitive market conditions, lack of attention to the transfer of soft technology, such as tacit knowledge and skills that drives the communicated technology development and the lack of capacity in technology due to lack of expert manpower and functional problem in the performance of the national innovation system.

Due to these reasons, a model was proposed for monitoring the effectiveness of technology transfer projects that include components of the holder of technology, technology, sensor technology, and process, transmit, transfer medium, the transfer agreement, the receiver technology, the holder of technology, macro environment, information and technology development process.

\section{References}

Mohammed Fathi Said Hatim light Mahdavi, 1391, Principles of Management, University of Science and Technology.

and Abbas Ali NAAMANI Khamse, 1389, to select the most appropriate mechanism for technology transfer to industry and decorative trim piece of the car (using AHP), the Fourth National Conference on Management of Technology, Tehran, Iran.

Azita Taghvai Gnjhly and R Qadiri, 1392, models (frameworks) and technology transfer model (a) appropriate technology transfer to industry, tire industry case study countries, the Third International Conference of the Seventh National Conference on Management of Technology, Kish Island.

Layla Namdaryan and S. Habib Tabatabaian, 1390, provided a model for successful technology transfer in developing countries, the International Conference on Fifth National Conference on Management of Technology, Tehran.

Renewable Energy Organization of Iran, 1392, the latest status of renewable energy by the end of 2012.

Morteza Safai Khalaji Asadi, B., 1382, installed wind power plants in Iran to investigate the technical and economic point of view, Eighteenth International Conference on Electrical, Tehran. 
Center for Wind Energy Association of Iran, 1391.

Center for Renewable Energy Organization of Iran, 1392. 